\title{
KUALITAS KERTAS SENI DARI PELEPAH TANAMAN SALAK MELALUI "BIOCHEMICAL" JAMUR Phanerochaete crysosporium DAN Pleurotus ostreatus DENGAN VARIASI LAMA PEMASAKAN DALAM NaOH
}

\author{
Triastuti Rahayu, Aulia Asifati Asifa \\ Prodi Pendidikan Biologi FKIP Universitas Muhammadiyah Surakarta \\ Jl. A. Yani Tromol Pos 1 Pabelan Kartasura Surakarta, 57162 \\ Email: $\underline{\text { tr124@ums.ac.id }}$
}

\begin{abstract}
Art paper or so-called recycled paper is paper commonly used as materials for handicrafts. Usually it made from crop wastes that contain high fiber. Waste plant frond bark utilized contain high fiber which can be utilized as raw material for paper making art. The raw material is processed through biopulping by fungus Phanerochaete crysosporium and Pleurotus ostreatus. The purpose of this study was to determine the quality of art paper from the midrib of zalacca through biochemical by fungus Phanerochaete crysosporium and Pleurotus ostreatus on variation of ripening duration in $\mathrm{NaOH}$ with tensile strength test, power tear and organoleptic test (texture, color, appearance fibers and acceptance of society). This research method used a completely randomized design (CRD) with two factors, one that is ripening duration in NaOH 15\% ( $P_{1}=1$ hour, $P_{2}=2$ hours) and factor 2 is a incubation duration ( $L_{1}=30$ days, $L_{2}=45$ days) with 4 treatment. Result of this research shows that the best quality art paper is $P_{2} L_{1}$ (ripeningduration time of 2 hours and 30-days incubation) is $0,243 \mathrm{~N} / \mathrm{mm}^{2}$ which is an tensile strengt test results and $18.711 \mathrm{~N}$ which is the highest tear power, smooth texture, light brown color, appearance of the fibers is less clear and panelists liked to this paper.
\end{abstract}

Keywords: biopulping, biochemical, art paper, midrib of zalacca, white rot fungi

\begin{abstract}
Abstrak
Kertas seni atau biasa disebut kertas daur ulang merupakan kertas yang biasa digunakan sebagai bahan pembuatan kerajinan tangan. Biasanya terbuat dari limbah tanaman yang mengandung serat tinggi. Limbah pelepah tanaman salak yangtidak termanfaatkan mengandung serat tinggi yang dapat dimanfaatkan sebagai bahan baku pembuatan kertas seni. Bahan baku tersebut diproses melalui biopulping jamur Phanerochaete crysosporium dan Pleurotus ostreatus. Tujuan dari penelitian ini adalah mengetahui kualitas kertas seni dari pelepah tanaman salak melalui biokraft jamur Phanerochaete crysosporium dan Pleurotus ostreatus dengan variasi lama pemasakan dalam $\mathrm{NaOH}$ dengan parameter penelitian uji daya tarik, daya sobek dan uji sensoris (tekstur, warna, kenampakan serat dan daya terima masyarakat). Metode penelitian ini menggunakan Rancangan Acak Lengkap (RAL) dengan dua faktor, faktor 1 yaitu lama pemasakan dalam $\mathrm{NaOH} 15 \%\left(\mathrm{P}_{1}=1\right.$ jam, $\mathrm{P}_{2}=2$ jam $)$ dan faktor 2 yaitu lama inkubasi $\left(\mathrm{L}_{1}=30\right.$ hari, $\mathrm{L}_{2}=45$ hari) dengan 4 perlakuan. Hasil penelitian menunjukkan bahwa kualitas kertas seni terbaik adalah pada perlakuan $\mathrm{P}_{2} \mathrm{~L}_{1}$ (lama pemasakan 2 jam dan lama inkubasi 30 hari) yaitu 0,243 N/ $\mathrm{mm}^{2}$ yang merupakan hasil uji daya tarik dan 18,711 N yang merupakan daya sobek tertinggi, tekstur halus, warna coklat muda, kenampakan serat kurang jelas dan panelis suka terhadap kertas ini.
\end{abstract}

Kata kunci: biopulping, biochemical, kertas seni, tanaman salak, jamur pelapuk putih 


\section{PENDAHULUAN}

Kertas seni atau biasa disebut kertas daur ulang merupakan kertas yang biasa digunakan sebagai bahan pembuatan kerajinan tangan. Kerajinan tangan yang bisa dibuat dari kertas seni antara lain tempat tisu, tas, kartu undangan, figura, accessories, dan perhiasan imitasi. Kertas ini terbuat dari berbagai macam serat tanaman. Oleh karena itu apabila kertas disobek akan menampakkan serat, serat inilah yang kemudian dikenal dengan selulosa. Bahan selulosa berasal dari bagian-bagian tanaman yang mengandung serat. Pada proses pembuatannya, bahan tersebut akan diolah menjadi pulp (bubur kertas) dengan bebebapa cara, yaitu chemical pulping, mechanical pulping dan biopulping. Chemical pulping merupakan pembuatan pulp secara kimia. Jika digunakan dalam produksi yang besar, dalam jumlah banyak dan dalam jangka waktu yang lama limbah dari zat-zat kimia tersebut akan berdampak pada pencemaran lingkungan.

Berbeda dengan chemical pulping, biopulping merupakan proses pengolahan pulp yang menggunakan mikroorganisme sebagai agen pelapuk. Tujuan dari biopulping adalah untuk memisahkan komponen lignin dari selulosa dan hemiselulosa. Dalam biopulping, bahan-bahan kimia tadi akan digantikan oleh sejenis mikroba yang mampu mengeluarkan enzim untuk memutihkan (manganese peroksidase, lakase, lignin peroksidase) dan juga mampu mendegradasi lignin. Mikroba tersebut adalah golongan jamur pelapuk kayu yang dapat dijumpai di alam. Hasil kerja dari mikroorganisme tersebut tidak menimbulkan pencemaran lingkungan dan sangat aman sehingga bisa dilakukan dalam waktu yang panjang. Phanerochaete crysosporium dan Pleurotus ostreatus merupakan jamur yang biasa dimanfaatkan dalam proses biopulping. Selanjutnya diikuti pemasakan kraft (pemasakan kimia) yang dapat membantu pendegradasian lignin. Lama pemasakan optimum dalam $\mathrm{NaOH}$ (alkali) adalah sekitar 60-120 menit (Dewi, dkk., 2010).

Bahan baku pembuatan kertas biasanya menggunakan kayu, sehingga penebangan hutan terjadi di mana-mana. Hal ini dapat berimbas menimbulkan bencana alam. Oleh karena itu perlu dicari bahan alternatif lain. Banyak sekali bahan berserat yang kurang maksimal pemanfaatannya, salah satunya adalah pelepah tanaman salak. Pada penelitian Raharjo, dkk. (2016), kandungan serat pelepah tanaman salak terdiri dari $42,54 \%$ selulosa, 34,35\% hemiselulosa dan 28,01\% lignin. Mengingat tingginya serat dan sejauh ini pemanfaatan limbah tersebut belum maksimal, maka hal inilah yang mendasari pemanfaatan pelepah tanaman salak sebagai bahan baku pembuatan kertas seni.

Penelitian ini bertujuan untuk menguji kualitas kertas seni dari pelepah tanaman salak melalui proses biopulping menggunakan kultur campuran jamur pelapuk putih berdasarkan parameter daya tarik, daya sobek, uji sensoris (tekstur, warna, kenampakan serat dan daya terima masyarakat). Hasil penelitian ini diharapkan akan diperoleh informasi tentang pengaruh penggunaan kultur campur jamur Phanerochaete crysosporium dan Pleurotus ostreatus dan lama pemasakan dalam $\mathrm{NaOH}$ terhadap kualitas kertas seni.

\section{METODE PENELITIAN}

Penelitian dilaksanakan di Laboratorium Biologi Program Studi Pendidikan Biologi Fakultas Keguruan dan Ilmu Pendidikan Universitas Muhammadiyah Surakarta. Penelitian 
dilaksanakan bulan November 2015 sampai Juli 2016. Jenis penelitian ini adalah eksperimen. Cacahan pelepah salak diinokulasi menggunakan campuran JPP $P$. crysosporium dan $P$. ostreatus $10 \%$ selama 30 dan 45 hari. Setelah inkubasi dibuat pulp dengan menggunakan $\mathrm{NaOH}$. Metode penelitian ini menggunakan Rancangan Acak Lengkap (RAL) dengan dua faktor, faktor 1 yaitu lama pemasakan dalam $\mathrm{NaOH}$ $15 \%\left(\mathrm{P}_{1}=1\right.$ jam, $\mathrm{P}_{2}=2$ jam $)$ dan faktor 2 yaitu lama inkubasi $\left(\mathrm{L}_{1}=30\right.$ hari, $\mathrm{L}_{2}=45$ hari) dengan 4 perlakuan. Analisis yang digunakan adalah deskriptif kuantitatif dan kualitatif. Parameter penelitian: 1) Uji Daya Tarik, 2) Uji Daya Sobek, dan 3) Uji Sensoris (tekstur, warna, kenampakan serat dan daya terima masyarakat).

\section{HASIL DAN PEMBAHASAN}

\section{Hasil Uji Daya Tarik dan Daya Sobek Kertas}

Pada penelitian kualitas kertas seni dari pelepah tanaman salak melalui biochemical jamur Phanerochaete crysosporium dan Pleurotus ostreatus dengan variasi lama pemasakan dalam $\mathrm{NaOH}$ ini, peneliti menggunakan pelepah tanaman salak yang berasal dari Turi, Sleman, Yogyakarta. Penelitian menggunakan 2 faktor yaitu lama pemasakan dalam $\mathrm{NaOH}$ (1 jam dan 2 jam) dan lama inkubasi 30 hari dan 45 hari. Parameter penelitian yakni daya tarik, daya sobek, dan sifat sensoris (tekstur, warna, kenampakan serat dan daya terima masyarakat terhadap kertas berbahan baku pelepah tanaman salak), diperoleh data sebagai berikut:

Tabel 1. Rata-Rata Uji Daya Tarik dan Daya Sobek Kertas Seni Pelepah Tanaman Salak dengan Lama Inkubasi dan Pemasakan yang Berbeda

\begin{tabular}{|c|c|c|}
\hline Perlakuan & $\begin{array}{c}\text { Rata-RataUji } \\
\text { Daya Tarik (N/ } \\
\left.\text { mm }^{2}\right)\end{array}$ & $\begin{array}{c}\text { Rata-Rata Uji } \\
\text { Daya Sobek (N) }\end{array}$ \\
\hline Kontrol Pemasakan 1 jam dan tanpa JPP $\left(\mathrm{P}_{1} \mathrm{~L}_{0}\right)$ & 0.205 & 14.485 \\
\hline Kontrol Pemasakan 2 jam dan tanpa JPP $\left(\mathrm{P}_{2} \mathrm{~L}_{0}\right)$ & 0.134 & 12.108 \\
\hline Pemasakan 1 jam dan inkubasi 30 hari $\left(\mathrm{P}_{1} \mathrm{~L}_{1}\right)$ & $0.129^{* *}$ & $11.740^{* *}$ \\
\hline Pemasakan 2 jam dan inkubasi 30 hari $\left(\mathrm{P}_{2} \mathrm{~L}_{1}\right)$ & $0.243^{*}$ & $18.711^{*}$ \\
\hline Pemasakan 1 jam dan inkubasi 45 hari $\left(\mathrm{P}_{1} \mathrm{~L}_{2}\right)$ & 0.141 & 12.825 \\
\hline Pemasakan 2 jam dan inkubasi 45 hari $\left(\mathrm{P}_{2} \mathrm{~L}_{2}\right)$ & 0.181 & 16.423 \\
\hline
\end{tabular}

Berdasarkan hasil penelitian, perlakuan $\mathrm{P}_{2} \mathrm{~L}_{1}$ (lama pemasakan 2 jam dan lama inkubasi 30 hari) yaitu 0,243 $\mathrm{N} / \mathrm{mm}^{2}$ yang merupakan hasil uji daya tarik dan 18,711 $\mathrm{N}$ yang merupakan daya sobek tertinggi. Sedangkan uji daya tarik terendah adalah pada perlakuan $\mathrm{P}_{1} \mathrm{~L}_{1}$ (lama pemasakan 1 jam dan lama inkubasi 30 hari) yaitu $0,129 \mathrm{~N} / \mathrm{mm}^{2}$, serta daya sobek terendah yakni 11,740 N. Pada perlakuan $\mathrm{P}_{1} \mathrm{~L}_{2}$ (lama pemasakan 1 jam dan lama inkubasi 45 hari) daya tariknya yaitu $0,141 \mathrm{~N} / \mathrm{mm}^{2}$ dan daya sobeknya 12,825 N. Sedangkan pada perlakuan $\mathrm{P}_{2} \mathrm{~L}_{2}$ (lama pemasakan 2 jam dan lama inkubasi 45 hari) daya tariknya yaitu 0,181 N/ $\mathrm{mm}^{2}$ dan daya sobeknya 16,423 N. Pada perlakuan kontrol $\mathrm{P}_{1} \mathrm{~L}_{0}$ (lama pemasakan 1 jam dan tanpa inkubasi) daya tariknya adalah $0,205 \mathrm{~N} / \mathrm{mm}^{2}$ dan daya sobeknya 14,485 N. Sedangkan pada perlakuan $\mathrm{P}_{2} \mathrm{~L}_{0}$ (lama pemasakan 2 jam dan tanpa inkubasi) daya tariknya adalah $0,134 \mathrm{~N} /$ $\mathrm{mm}^{2}$ dan daya sobeknya yaitu $12,108 \mathrm{~N}$. 
Jika dibandingkan pada perlakuan lama inkubasi 30 hari $\left(\mathrm{L}_{1}\right)$, antara lama pemasakan 1 jam $\left(\mathrm{P}_{1}\right)$ dengan lama pemasakan 2 jam $\left(\mathrm{P}_{2}\right)$, mengalami peningkatan nilai daya tarik dan daya sobek. Perlakuan lama pemasakan 1 jam $\left(\mathrm{P}_{1}\right)$ mempunyai nilai daya tarik $0,129 \mathrm{~N} / \mathrm{mm}^{2}$ dan daya sobek $11,740 \mathrm{~N}$, sedangkan pada lama pemasakan 2 jam $\left(\mathrm{P}_{2}\right)$ nilai daya tariknya $0,243 \mathrm{~N} / \mathrm{mm}^{2}$ dan daya sobeknya 18,711 . Jika diamati hal ini juga terjadi pada perlakuan lama inkubasi 45 hari $\left(\mathrm{L}_{2}\right)$. Lama pemasakan 2 jam mempunyai daya tarik dan daya sobek yang lebih tinggi dibandingkan 1 jam. Hal ini menunjukkan bahwa selama proses biopulping menggunakan Pleurotus ostreatus dan Phanerochaete crysosporium lignin yang terdegradasi tinggi, diperkuat dengan proses kraft selama 2 jam menyebabkan kemungkinan kandungan selulosa semakin meninggi (Dewi, dkk., 2010), sehingga daya tarik dan daya sobek kertas semakin tinggi.

Berbeda halnya pada perlakuan kontrol yang tanpa mengalami proses biopulping. Pada perlakuan $\mathrm{P}_{1} \mathrm{~L}_{0}$ (lama pemasakan 1 jam dan tanpa JPP) mempunyai nilai daya tarik $0,205 \mathrm{~N} / \mathrm{mm}^{2}$ dan daya sobek 14,485 N. Sedangkan pada perlakuan $\mathrm{P}_{2} \mathrm{~L}_{0}$ (lama pemasakan 2 jam dan tanpa JPP) mempunyai nilai daya tarik $0,134 \mathrm{~N} / \mathrm{mm}^{2}$ dan daya sobek 12,108 N. Kontrol mengalami penurunan nilai daya tarik dan daya sobek. Hal ini membuktikan bahwa semakin tinggi lama pemasakannya, maka rendemen pulp yang dihasilkan cenderung makin tinggi, kandungan lignin juga semakin tinggi. Lignin yang semula terpisah dari raw pulp dengan berkurangnya konsentrasi $\mathrm{NaOH}$ akan kembali menyatu dengan raw pulp dan sulit untuk dipisahkan kembali (Dewi, dkk.2010). Hal ini sesuai dengan pendapat Citra (2000), bahwa lignin merupakan senyawa penghambat ikatan antar serat, menyebabkan serat menjadi kaku, dan serat sukar pecah saat penggilingan. Bila serat sukar pecah, maka akan menyebabkan ikatan antar serat menjadi lebih rendah. Karena hal inilah, daya tarik dan daya sobek kertas yang tanpa adanya proses biopulping (pendegradasian lignin oleh jamur) menjadi lebih rendah.

Dalam pembuatan kertas seni dari pelepah tanaman salak ini, proses biokraft yang menggunakan jamur Pleurotus ostreatus dan Phanerochaete crysosporium lebih efektif dalam proses pendegradasian lignin dibandingkan dengan pembuatan kertas tanpa melalui biopulping. Karena menurut Fatriasari (2010), jamur memfasilitasi penghilangan lignin pada dinding sel sehingga proses pulping kraft lebih efektif. Fasilitas tersebut dikeluarkan jamur dalam bentuk enzim yang mampu mendegradasi lignin. Enzim ligninolitik antara lain laccase, lignin peroksidase (LiP) dan mangan peroksidase (MnP). Lignin peroksidase (LiP) yang secara imunologis dan struktural berbeda dari mangan, menunjukkan kemampuan mengoksidasi bagian ikatan lignin. Sedangkan peran $\mathrm{MnP}$ dalam mendegradasi lignin secara tidak langsung dengan menyediakan $\mathrm{H}_{2} \mathrm{O}_{2}$ untuk reaksi ligni peroksidase (Hossain dan Anantharaman, 2006).

Diperkuatjuga dengan hasil penelitian Fahmi (2016), pada lama pemasakan 2 jam dalam $\mathrm{NaOH}$ 10\% (inkubasi jamur POPC 30 hari) hasil uji rata-rata daya tariknya adalah $0,05 \mathrm{~N} / \mathrm{mm}^{2}$, dibandingkan dengan perlakuan sama namun konsentrasi $\mathrm{NaOH}-n y a 15 \%$ daya tarik naik menjadi $0,24 \mathrm{~N} / \mathrm{mm}^{2}$. Sedangkan pada lama pemasakan 2 jam dalam $\mathrm{NaOH} 10 \%$ (inkubasi jamur POPC 45 hari) hasil uji rata-rata daya tariknya adalah $0,22 \mathrm{~N} /$ $\mathrm{mm}^{2}$, dibandingkan dengan perlakuan sama namun konsentrasi $\mathrm{NaOH}-n y a$ $15 \%$ daya tarik turun menjadi $0,18 \mathrm{~N} /$ 
$\mathrm{mm}^{2}$. Semakin lama inkubasi (45 hari), hanya diperlukan konsentrasi $\mathrm{NaOH}$ $10 \%$ agar daya tariknya tinggi. Hal ini menunjukkan bahwa biopulping sangat efektif digunakan dalam pembuatan kertas seni ini.

Selain adanya proses biopulping (lama inkubasi) dan proses kraft (lama pemasakan). Proses pengepresan kertas juga mempengaruhi daya tarik maupun daya sobek kertas seni. Hal ini diungkapkan pada penelitian Sutyasmi (2012), bahwa indeks retak/ sobek dan indeks tarik kertas seni yang dipres mempunyai hasil yang lebih baik dibandingkan dengan kertas seni yang tidak dipres. Hal ini karena kemungkinan karena serat-serat kulit dan serat selulosa bisa saling berkaitan dengan adanya pengepresan.

\section{Uji Sensoris}

Uji sensoris merupakan cara pengujian menggunakan indera manusia sebagai sarana untuk mengukur daya penerimaan terhadap suatu produk yang diujikan. Pada penelitian ini menggunakan uji sensoris karena peneliti ingin mengetahui bagaimana daya terima masyarakat terhadap kertas seni dari pelepah tanaman salak. Uji sensoris tersebut meliputi tekstur, warna, kenampakan serat dan daya terima masyarakat.

Tabel 2. Rata-Rata Uji Sensoris Kertas Seni Pelepah Tanaman Salak dengan Lama Inkubasi dan Pemasakan yang Berbeda

\begin{tabular}{|c|c|c|c|c|}
\hline \multirow{2}{*}{ Perlakuan } & \multicolumn{4}{|c|}{ Rata-Rata Uji Sensoris } \\
\hline & Tekstur & Warna & Kenampakan Serat & Daya Terima \\
\hline $\mathrm{P}_{1} \mathrm{~L}_{0}$ & $(1,5)$ Halus $^{* *}$ & $(1,9)$ Coklat muda & (2) Kurang tampak & Kurang suka \\
\hline $\mathrm{P}_{2} \mathrm{~L}_{0}$ & $(1,7)$ Halus & $(1,7)$ Coklat muda** & $(2,05)$ Kurang tampak* & Kurang suka** \\
\hline $\mathrm{P}_{1} \mathrm{~L}_{1}$ & $(1,9)$ Halus & $(1,9)$ Coklat muda & $(1,9)$ Kurang tampak & Sangat suka* \\
\hline $\mathrm{P}_{2} \mathrm{~L}_{1}$ & $(2,05)$ Halus* & $(2,2)$ Coklat muda* & (2) Kurang tampak & Suka \\
\hline $\mathrm{P}_{1} \mathrm{~L}_{2}$ & $(1,8)$ Halus & $(1,8)$ Coklat muda & $(1,9)$ Kurang tampak & Sangat suka* \\
\hline $\mathrm{P}_{2} \mathrm{~L}_{2}$ & $(1,9)$ Halus & $(2,05)$ Coklat muda & $(1,8)$ Kurang tampak ${ }^{* *}$ & Kurang suka \\
\hline
\end{tabular}

Hasil dari penilaian panelis terhadap semua perlakuan menunjukkan bahwa tekstur kertas seni adalah halus (gambar 1). Pada perlakuan $\mathrm{P}_{2} \mathrm{~L}_{1}$ (lama pemasakan 2 jam dan inkubasi 30 hari) jumlah rata-rata skor adalah 2,05, angka ini menunjukkan tingkat yang mendekati sangat halus. Sedangkan pada kontrol $\mathrm{P}_{1} \mathrm{~L}_{0}$ (lama pemasakan 1 jam dan tanpa JPP) jumlah rata-rata skornya adalah 1,5. Angka ini berarti menunjukkan bahwa kertas seni tanpa biopulping dan pemasakan 1 jam, cenderung mempunyai tekstur yang kasar. Kertas seni yang mempunyai tekstur kasar umumnys lebih disukai konsumen, karena mempunyai nilai seni yang lebih tinggi (Sukmani, 2000).
Tekstur permukaan sangat dipengaruhi oleh teknik mencetak dan ukuran serat (Smook, 1994). Selain itu pada perlakuan kontrol yang tidak melalui proses biopulping (pelapukan jamur) cenderung agak kasar, hal ini kemungkinan disebabkan karena belum adanya aktivitas pendegradasian lignin, sehingga proses kraft saja kurang efektif untuk menghilangkan lignin yang menyebabkan serat lebih sulit terpecah. Hal ini juga mempengaruhi tingkat kekasaran tekstur kertas. 


\section{Lama pemasakan dalam $\mathrm{NaOH} 15 \% 1$ jam $\left(P_{1}\right)$}

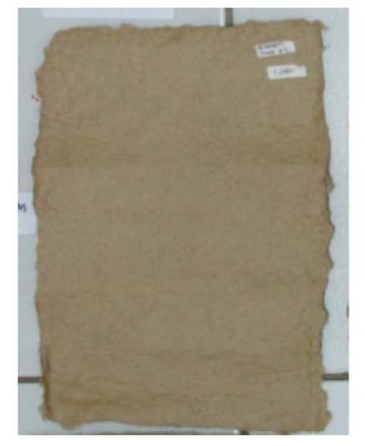

Kontrol

(a)

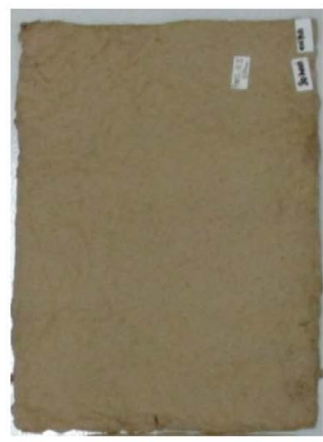

30 hari

(b)

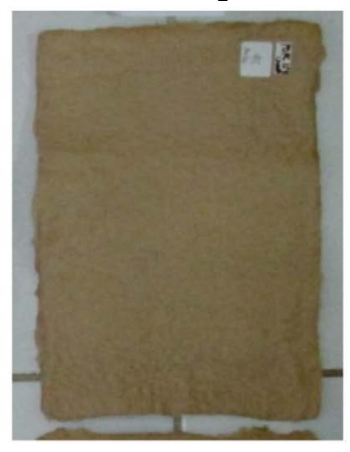

45 hari

(c)

Lama pemasakan dalam $\mathrm{NaOH} 15 \% 2$ jam $\left(\mathrm{P}_{2}\right)$

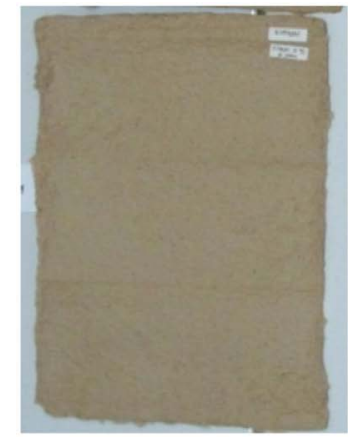

Kontrol

(d)

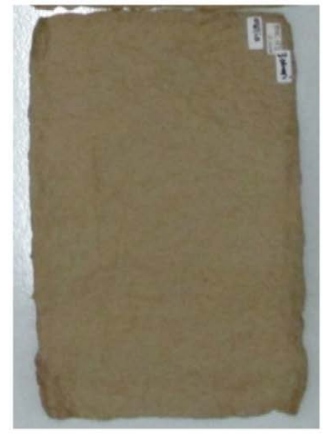

30 hari

(e)

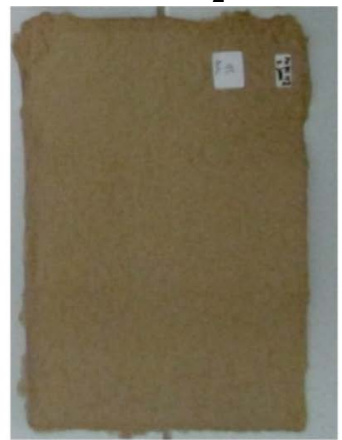

45 hari

(f)

\section{Keterangan: (a) $P_{1} L_{0^{\prime}}$ (b) $P_{1} L_{1^{\prime}}$ (c) $P_{1} L_{2^{\prime}}$ (d) $P_{2} L_{0^{\prime}}$ (e) $P_{2} L_{1^{\prime}}$ (f) $P_{2} L_{2}$}

Gambar 1. Hasil kertas seni dari pelepah tanaman salak dengan berbagai perlakuan yang berbeda

Dari hasil penilaian panelis, warna kertas seni dari pelepah tanaman salak merupakan coklat muda. Adapun ratarata nilai yang menunjukkan warna coklat cenderung tua adalah pada perlakuan $\mathrm{P}_{2} \mathrm{~L}_{1}$ (lama pemasakan 2 jam dan inkubasi 30 hari) dengan ratarata skor 2,2. Sedangkan warna yang cenderung mendekati putih adalah pada kontrol $\mathrm{P}_{2} \mathrm{~L}_{0}$ (lama pemasakan 2 jam dan tanpa JPP) dengan rata-rata skor 1,7.

Pada penelitian ini menunjukkan bahwa kertas seni yang dibuat melalui proses biopulping menghasilkan warna yang lebih tua daripada control. Hal ini bertentangan dengan penelitian Fatriasari (2010), yang mengungkapkan bahwa lama inkubasi memiliki pengaruh positif terhadap derajat putih pulp perlakuan POPC. Karena enzim yang dihasilkan oleh jamur PC mampu meningkatkan kecerahan pulp yang disebabkan penurunan lignin. Adanya perbedaan hasil penelitian ini kemungkinan disebabkan karena belum optimalnya aktivitas/ kerja kedua jamur pada masa inkubasi.

Berdasarkan tabel 2 dan gambar 1, panelis sangat suka terhadap kertas seni dengan perlakuan $\mathrm{P}_{1} \mathrm{~L}_{1}$ (lama pemasakan 1 jam dan inkubasi 30 hari) dan $\mathrm{P}_{1} \mathrm{~L}_{2}$ (lama pemasakan 1 jam dan inkubasi 45 hari). Kesukaan panelis terhadap kertas seni bergantung pada penilaian 
individu panelis yang dipengaruhi oleh cirri fisik kertas, yakni tekstur, warna dan kenampakan serat. Selain itu, Sucipto (2009) menyebutkan bahwa ketebalan kertas juga mempengaruhi penilaian panelis karena tergantung pada pemanfaatannya.

Kertas seni dari pelepah tanaman salak yang diolah melalui proses bio-chemical lebih efektif dilakukan dibandingkan hanya dimasak dengan proses kraft tanpa biopulping.

\section{PENUTUP}

Berdasarkan hasil dan pembahasan dari penelitian ini, dapat disimpulkan bahwa: Kualitas kertas seni terbaik adalah pada perlakuan $\mathrm{P}_{2} \mathrm{~L}_{1}$ (lama pemasakan 2 jam dan lama inkubasi 30 hari) yaitu $0,243 \mathrm{~N} / \mathrm{mm}^{2}$ yang merupakan hasil uji daya tarik dan 18,711 $\mathrm{N}$ yang merupakan daya sobek tertinggi, tekstur halus, warna coklat muda, kenampakan serat kurang jelas dan panelis suka terhadap kertas ini.

Berdasarkan pengalaman selama penelitian, ada beberapa saran dari peneliti yang perlu disampaikan: 1) Perlu dilakukan penelitian lebih lanjut untuk menguji adanya pengaruh lama inkubasi dan lama pemasakan dalam konsentrasi $\mathrm{NaOH}$ yang berbeda terhadap kualitas kertas seni, 2) Perlu dilakukan penelitian lebih lanjut untuk menguji kadar lignin yang terdegradasi karena perbedaan lama inkubasi dan lama pemasakan dalam konsentrasi $\mathrm{NaOH}$ yang berbeda, 3) Dalam proses inkubasi jamur pelapuk putih diusahakan suhu dan kelembabannya terjaga (sesuai dengan syarat tumbuh jamur), 4) Untuk menghindari kontaminasi, pastikan saat penelitian menggunakan tempat yang sudah disterilkan.

\section{UCAPAN TERIMAKASIH}

Terimakasih kepada keluarga, dosen FKIP Pendidikan Biologi UMS, dan teman-teman yang telah memberi bantuan untuk penelitian skripsi dan penulisan artikel ilmiah.

\section{DAFTAR PUSTAKA}

Citra, R.P., 2000. Kajian Pengaruh Jenis dan Konsentrasi Kapang Pelapuk Putih Terhadap Biodelignifikasi Kayu Mangium (Acacia mangium Willd). Skripsi. Fakultas Teknologi Pertanian. Institut Pertanian Bogor.

Dewi, Tri K., Dandy, dan Wahyu Akbar. 2010. Pengaruh Konsentrasi $\mathrm{NaOH}$, Temperatur Pemasakan dan Lama Pemasakan pada Pembuatan Pulp dari Batang Rami dengan Proses Soda. Jurnal Teknik Kimia , No. 2, Vol. 17, April 2010.

Fahmi, M. Saiful. 2016. Kualitas Kertas Seni dari Pelepah Tnaman Salak Melalui Biokraft Jamur Phanerochaete crysosporium dan Pleurotus ostreatus dengan Variasi Konsentrasi $\mathrm{NaOH}$. Skripsi. Universitas Muhammadiyah Surakarta. Surakarta.

Fatriasari. W., Anita. S.H., Falah. F., Adi. T.N., dan Hermiati. E. 2010. Biopulping Bambu Betung Menggunakan Kultur Campur Jamur Pelapuk Putih (Trametes versicolor, Pleurotus ostreatus dan Phanerochaete crysosporium). Berita Selulosa, Vol. 45, No. 2, Desember $2010: 44-56$.

Febrina, P. 2007. Studi Pembuatan Kertas Seni dari Batang Jagung (Zea mays) dan Ampas Tebu (Saccharum officinarum) (Kajian Proporsi Bahan Baku dan Jenis Perekat). Skripsi. Fakultas teknologi Pertanian. Universitas Brawijaya. Malang. 
Smook, G. A. 1992. Handbook for Pulp E Paper Technologists. Second Edition. Angus Wilde Publications.

Sucipto, Susinggih W., dan Erly W. 2009. Optimasi Penggunaan $\mathrm{NaOH}$ dan Tapioka pada Produksi Kertas Seni dari Pelepah Salak. Jurnal teknologi Pertanian vol. 10 No. 1 (April 2009), 46-53.

Sukmani, N. A., 2000. Perancangan Produk Kertas Seni dari Ampas Umbi Garut (Maranta arundinaceae): Kajian Lama Pemanasan dan Konsentrasi Larutan $\mathrm{NaOH}$ Serta Analisis Finansialnya. Skripsi. Fakultas Teknologi Industri Pertanian. Universitas Brawijaya. Malang.

Sutyasmi, S., 2012. Daur Ulang Limbah Shaving Industri Penyamakan Kulit untuk Kertas Seni. Majalah Kulit, Karet dan Plastik Vol28 No.2 Desember Tahun 2012:113-121. 